\title{
The different mechanisms of insulin sensitizers to prevent type 2 diabetes in OLETF rats
}

\author{
Sung Hee Choi ${ }^{1}$ \\ Zheng Shan Zhao ${ }^{2}$ \\ Yong Jik Lee ${ }^{2}$ \\ Soo Kyung Kim ${ }^{3}$ \\ Dae Jung Kim ${ }^{4}$ \\ Chul Woo Ahn' ${ }^{2,5}$ \\ Sung Kil Lim ${ }^{2,5}$ \\ Hyun Chul Lee 2,5 \\ Bong Soo $\mathrm{Cha}^{2,5 *}$ \\ ${ }^{1}$ Division of Endocrinology and \\ Metabolism, Department of Internal \\ Medicine, Seoul National University \\ College of Medicine, Bundang \\ Hospital, Seongnam, Korea \\ ${ }^{2}$ Division of Endocrinology and \\ Metabolism, Department of Internal \\ Medicine, Yonsei University College, \\ Seoul, Korea \\ ${ }^{3}$ Division of Endocrinology and \\ Metabolism, Department of Internal \\ Medicine, College of Medicine Pochon \\ Cha University, Korea \\ ${ }^{4}$ Division of Endocrinology and \\ Metabolism, Department of Internal \\ Medicine, Ajou University School of \\ Medicine, Suwon, Korea \\ ${ }^{5}$ BK 21 Project for Medical Science, \\ Yonsei University College of Medicine, \\ Seoul, Korea \\ *Correspondence to: Bong Soo Cha, \\ Department of Internal Medicine, \\ School of Medicine, Yonsei \\ University, 134, Shinchon-Dong, \\ Seodaemoon-Ku, Seoul, Korea. \\ E-mail: bscha@yumc.yonsei.ac.kr
}

WILEY

InterScience

Received: 8 June 2006

Revised: 27 February 2007

Accepted: 16 April 2007

\begin{abstract}
Objective To investigate the effects of pioglitazone and metformin treatment during pre-diabetic period for the prevention of diabetes in a rat model.

Methods OLETF rats aged 18-weeks, were treated with pioglitazone $(10 \mathrm{mg} / \mathrm{kg} /$ day $)$ and metformin $(300 \mathrm{mg} / \mathrm{kg} / \mathrm{day})$ for 10 weeks from their pre-diabetic period. We measured weight, lipid profiles, fat distribution, glucose tolerance, and pancreatic insulin content.

Results Prominent weight gain (mostly subcutaneous fat area) was observed in the pioglitazone-treated OLETF (O-P) rats versus significant weight loss was observed in the metformin-treated OLETF (O-M) rats. Pioglitazone reversed the serum triglyceride (TG) and FFAs levels to normal (TG $0.46 \pm 0.04$ vs $0.88 \pm 0.05 \mathrm{mmol} / \mathrm{l}$ in LETO). At the age of 28 weeks, the O-P rats showed completely normal glucose tolerance, and the glucose disposal rate (GDR) was markedly improved $(25.6 \pm 0.4 v s 20.6 \pm 0.5 \mathrm{mg} / \mathrm{min} / \mathrm{kg}$ in O-C, $p<0.05)$. The O-M rats also showed an improved fasting glucose and GDR level, but not as much as those with O-P rats. The pancreas insulin contents were much improved in the O-P rats $(22.9 \pm 1.2 v s 18.8 \pm 1.3 \mathrm{nmol} /$ pancreas in O-M rats, $p<0.05$ ) with histological improvement.
\end{abstract}

Conclusion The pre-diabetic treatment with pioglitazone, despite significant weight gain, completely prevents to develop diabetes and enhances beta cell function with preservation of islet cell changes. Metformin treatment was also effective, but mainly by ameliorating the insulin resistance with marked reduction in body weight. The reversal of dyslipidaemia and the fat redistribution might contribute to the greater improvement of pioglitazone treatment compared to metformin in OLETF rats. Copyright @ 2007 John Wiley \& Sons, Ltd.

Keywords prevention of diabetes; dyslipidaemia; OLETF rats; pioglitazone; metformin

\section{Introduction}

Type 2 diabetes mellitus is a chronic, slowly progressive disease that is caused by both insulin deficiency and insulin resistance. The incidence of diabetes has been increasing rapidly, and the cost of managing the chronic complications associated with diabetes is also becoming an enormous problem. Therefore, it would be important to identify the high-risk patients in pre-diabetic stage and focus on the prevention of type 2 diabetes through life-style modifications or medication [1]. 
The male Otsuka Long-Evans Tokushima Fatty (OLETF) rat is a good animal model for examining obese type 2 diabetes mellitus. These rats are characterized by their polygenic traits, chronic, and late onset of disease [2,3]. Between 20 and 28 weeks of age, they begin to have overt diabetes, and around the age of 40 weeks, pancreatic beta cell function apparently decreases and becomes hypoinsulinaemic with defects in insulin secretion [3].

Several clinical and animal studies have shown that troglitazone, peroxisome proliferator-activated receptor (PPAR) $-\gamma$ agonist, prevents the progression of type 2 diabetes through various mechanisms [4-8]. Pioglitazone belongs to the thiazolidinedione class of drugs and binds to a nuclear receptor called the PPAR- $\gamma$. It enhances the expression of multiple genes encoding the proteins that modulate glucose and lipid metabolism $[9,10]$. Pioglitazone increases insulin sensitivity mainly at the level of muscle and adipose tissue, with some effects on the liver. However, the accurate mechanism of this drug is still unclear [11-13]. Pioglitazone is also known to have some effects related to the PPAR- $\alpha$ receptor. This cross reactivity to the PPAR- $\alpha$ may explain why pioglitazone more effectively lowers triglyceride levels in this class $[14,15]$. Metformin is also widely used as an insulin sensitizer in clinics; There are several studies which have shown that metformin can prevent diabetes mellitus and hypertension in animals and humans [16-18].

Therefore, the aims of our study were to investigate and compare the metabolic effects of well-known insulin sensitizers, pioglitazone and metformin, and their effectiveness in preventing the development of diabetes in genetically determined diabetic OLETF rats with chronic treatment from the pre-diabetic periods.

\section{Materials and methods}

\section{Animals and diet}

Male OLETF rats and their control counterpart, male LongEvans Tokushima Otsuka (LETO) rats, aged 4 weeks, were kindly provided from Otsuka Pharmaceuticals, Japan. They were maintained in a temperature-controlled environment with a 12-h light/dark cycle and supplied with standard rat chow diet consisting of $61 \%$ carbohydrate, $26 \%$ protein and $13 \%$ fat and tap water ad libitum. They were maintained according to the ethical guidelines of this institution. The Committee on Animal Investigation of the Yonsei University approved this experimental protocol.

\section{Administration of pioglitazone and metformin}

Pioglitazone, [( \pm )-5-[p-[2-(5-ethyl-2-pyridyl)ethyl]benzyl]-2.4-thiazolinedione hydrochloride], which is known as a PPAR $-\gamma$ agonist, was kindly provided by Dr Hiroshi Fukui (Takeda Chemical Industry Co., Osaka, Japan). Standard rat chow was pulverized to a fine powder and divided into two groups, pioglitazone and metformin. The respective drugs were added and thoroughly mixed to a final concentration of $0.015 \%$ (wt/wt) [piolitazone $150.02 \mathrm{mg} /$ pulverized chow $1 \mathrm{~kg}$ ] and $0.677 \%$ (wt/wt) [metformin $6.816 \mathrm{~g} /$ pulverized chow $1 \mathrm{~kg}$ ], respectively. These concentrations were chosen based on a preliminary study that adjusted the pioglitazone and metformin doses to 10 and $300 \mathrm{mg} / \mathrm{kg} /$ day, respectively. The chow for control rats was prepared in a similar manner without the addition of drugs.

\section{Experimental protocol}

At the age of 18 weeks, the OLETF rats were randomly divided. The LETO control rats (LETO) and OLETF control rats (O-C) received standard chow diet only from birth to 28 weeks ( $n=10$ at each). The Pioglitazone treated OLETF rats (O-P) were maintained on the pioglitazonecontaining chow diet $(n=20,0.015 \%$, wt/wt) and the metfomin treated OLETF rats (O-M) received metformincontaining chow ( $n=20,0.677 \%$, wt/wt) from 18 to 28 weeks of age. All the rats were housed two to a cage and were given free access to chow and water. The body weight and food intake of the OLETF and LETO rats were monitored periodically from the age of 18 to 28 weeks. The mean food intake was estimated to be the amount of food consumed per cage. At the ages of 18 and 28 weeks, an oral glucose tolerance test (OGTT) was performed in all groups, respectively. A euglycaemic hyperinsulinaemic clamp test was performed at the age of 28 weeks. After the euglycaemic clamp test, all rats were sacrificed and the abdomen was quickly opened to remove the whole pancreas ( $n=10$ from each group). The abdominal subcutaneous fat pad and epididymal visceral fat pad were dissected and weighed.

\section{Plasma glucose and lipid measurements}

Blood was withdrawn from the tail vein and the blood sample was placed on ice prior to centrifugation for $10 \mathrm{~min}$. The supernatant was retained and stored at $-80^{\circ} \mathrm{C}$ until the glucose, insulin, total cholesterol (TC), triglyceride (TG), and non-esterified free fatty acids (FFAs) levels were measured. The plasma glucose level was measured by a glucose-oxidase method. The plasma insulin concentration was measured by a radioimmunoassay using the double-antibody method with a commercially available radioimmunoassay kit (Linco Research). The plasma concentrations of total cholestrol, TG, and FFAs were measured by an enzymatic colorimetric method using commercially available kits.

\section{Euglycaemic-hyperinsulinaemic clamp test}

After 10 weeks of treatment, the rats were anesthetized with sodium pentobarbital (Somnotol; $50 \mathrm{mg} / \mathrm{kg}$, ip). The 
body temperature was maintained at $37-38^{\circ} \mathrm{C}$ with a heating lamp. The right femoral artery was catheterized for blood sampling. A blood sample was obtained $20 \mathrm{~min}$ after surgery to determine the basal blood glucose concentration. Insulin was infused at a constant rate of $6 \mathrm{mU} / \mathrm{kg} / \mathrm{m}$ via the left femoral artery with an infusion pump (Harvard Apparatus 22; Harvard, Natick, MA). Human insulin was dissolved in $0.9 \% \mathrm{NaCl}$ containing $1 \%$ BSA. The glucose (25\%, wt/vol) infusion was begun $5 \mathrm{~min}$ after the insulin infusion through a second IV catheter with its infusion rate adjusted to sustain the plasma glucose level at $-6 \mathrm{mmol} / \mathrm{l}$ using the PACBERG algorithm. Subsequently, $25 \mu \mathrm{l}$ blood was sampled from the right femoral artery at 10-min intervals, and the blood glucose concentrations were determined within $30 \mathrm{~s}$ using a glucose analyser $[19,20]$.

\section{Pancreas Insulin content}

After a 2-h euglycaemic clamp test, the rats were sacrificed ( $n=7$ in each LETO and O-C group, $n=10$ in each O$\mathrm{P}$ and $\mathrm{O}-\mathrm{M}$ group) and the whole pancreas was rapidly dissected free from the surrounding tissues, weighed in air, frozen in liquid N2, and stored at $-70^{\circ} \mathrm{C}$. The frozen whole pancreata were homogenized at $20500 \mathrm{rpm}$ for 20 s using a tissue homogenizer (Ultra-Turrax T24, IKALabartechnik, Staufen, Germany) in a 10 times volume (10 ml buffer solution per $1 \mathrm{~g}$ tissue) of an acid ethanol

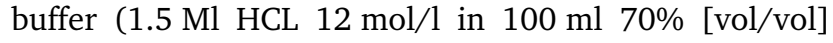
ethanol) and incubated overnight at $4{ }^{\circ} \mathrm{C}$ for a further extraction. On the next day, the samples were centrifuged at $3000 \mathrm{~g}$ for $15 \mathrm{~min}$ at $4{ }^{\circ} \mathrm{C}$, and the supernatants were diluted $1: 100$ and refrozen at $-70^{\circ} \mathrm{C}$ until needed for the assay. The insulin level was measured with an insulin RIA kit for rat insulin and was normalized with the pancreas and the total body weight $(\mathrm{g} \%)$.

\section{Histopathological examination}

Pancreatic tissues ( $n=3$ in each LETO and O-C group, $n=10$ in each O-P and O-M group) were fixed overnight in $10 \%$ formaldehyde solution and embedded in paraffin for histological examination. Paraffin sections were stained with hematoxylin-eosin (H\&E) stain and Masson's trichrome stain to evaluate the degree of fibrotic change. All histological samples were examined by the same pathologist who was blinded to the treatment.

\section{Statistical analysis}

The inter-group comparisons were performed using an independent samples $t$-test and a one-way ANOVA. Paired samples were compared with using a paired $t$ test. Significance was defined as a $p$ value $<0.05$. The group data is expressed as a mean \pm SEM. The statistical analyses were performed using the SPSS 10.0 software package (SPSS, Inc., Chicago, IL).

\section{Results}

\section{Food consumption and body weight changes}

During the period of study, the mean daily food intake of the LETO and OLETF rats was similar $(28.3 \pm 1.1$ (vs) $29.5 \pm 1.5 \mathrm{~g} / \mathrm{d}, \mathrm{P}=\mathrm{NS}$ ). Chronic treatment with pioglitazone and metformin did not influence the quantity of food intake $(26.9 \pm 1.3,26.8 \pm 1.6 \mathrm{~g} / \mathrm{d}$, respectively, Table 1). The O-P gained more weight at the end of the study than the O-C $(600 \pm 14$ (vs) $528 \pm 14 \mathrm{~g}$ in $\mathrm{O}-\mathrm{C}$ rats, $\mathrm{p}<0.05)$. Meanwhile, the $\mathrm{O}-\mathrm{M}$ failed to gain weight compared to the control-OLETF rats $(506 \pm 18 \mathrm{~g}$ (vs) $528 \pm 14 \mathrm{~g}$ in O-C rats, $p<0.05$, Table 1 ).

\section{Body fat distribution}

The prominent weight gain in the OLETF rats after pioglitazone treatment was primarily due to the increase in the subcutaneous fat deposit rather than the visceral one $(4.7 \pm 0.1(v s) 3.0 \pm 0.3 \mathrm{~g} \%$ in O-C rats, $p<0.05$, Table 1). The epididymal fat contents were markedly lower in the metformin-treated OLETF rats compared to the other group $(1.8 \pm 0.1(v s) 2.5 \pm 0.1 \mathrm{~g} \%$ in O-P rats, $p<0.05$, Table 1$)$.

\section{Serum insulin and glucose response to oral glucose load}

At the beginning of the study, the baseline plasma glucose concentration and glucose intolerance of the LETO and OLETF rats were similar (Table 1, Figure 1(A)). At the end of the study, the fasting plasma glucose levels of the $\mathrm{O}-\mathrm{C}$ rats were slightly higher than that in the LETO rats (5.81 $\pm 0.11(v s) 4.43 \pm 0.21 \mathrm{mmol} / \mathrm{l}, p<0.05$, Table 1$)$. However, after an oral glucose load, the blood glucose level was remarkably higher in the O-C rats than the LETO rats (Figure $1(\mathrm{~B})$ ). In contrast to the $\mathrm{O}-\mathrm{C}$ rats, the O-P rats showed almost normal fasting and glucose-loaded blood glucose levels compared to those of the LETO rats (Figure 1(B)). In the case of the O-M rats, the fasting glucose level was similar to those in the O-P rats, in which the post glucose-loaded levels were between those of the O-C and O-P rats, but the peak blood glucose levels was almost $16 \mathrm{mmol} / \mathrm{l}$ at $30 \mathrm{~min}$ after the glucose load (Figure 1(B)).

From an analysis of the glucose area under the curve (AUC), the O-P rats showed a marked improvement in the glucose utilization rather than the O-M rats $(7.15 \pm 0.98$ (vs) $11.02 \pm 0.75 \mathrm{mmol} / \mathrm{l} / \mathrm{h}$, respectively, $\mathrm{p}<0.05$, Table 1$)$

\section{Changes of plasma lipid concentrations}

At the pre-diabetic stage of the 18-week-old OLETF rats, the fasting total cholesterol and triglyceride plasma 


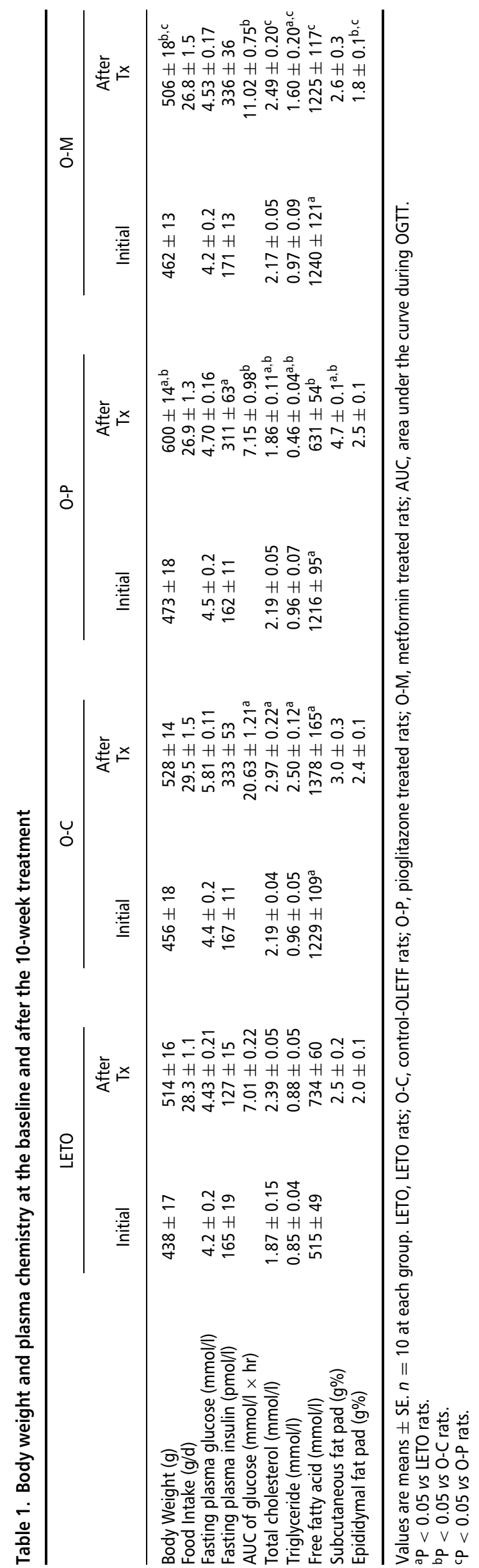

concentrations of the OLETF and LETO rats were similar (Table 1). However, the fasting plasma-free fatty acid levels of the OLETF rats were markedly higher than the LETO rats. At the end of the study, the fasting total cholesterol, triglyceride, and free fatty acid plasma levels in the $\mathrm{O}-\mathrm{C}$ rats were remarkably elevated compared to those of the LETO rats (Table 1). After 10 weeks of pioglitazone administration, the lipid profiles of the O$P$ rats, particularly the serum triglyceride levels and FFAs, were dramatically improved and reversed up to the lower levels than those of the LETO control rats (TG $0.46 \pm 0.04(v s) 0.88 \pm 0.05 \mathrm{mmol} / \mathrm{l}$ in LETO, $P<0.05$, Table 1). In the O-M rats, the plasma lipid concentrations were also reduced, but not as profound as those in O-P rats (Table 1).

\section{Glucose disposal rate during euglycaemic clamp test}

In the $\mathrm{O}-\mathrm{C}$ rats, the glucose disposal rate was significantly lower during the euglycaemic clamp test than in the non-diabetic LETO rats (20.6 \pm 0.5 (vs) $26.3 \pm$ $0.4 \mathrm{mg} / \mathrm{min} / \mathrm{kg}, p<0.05$, Figure 2). Both the O-P and $\mathrm{O}-\mathrm{M}$ rats recovered the glucose disposal rate up to the level of those in the LETO rats (Figure 2).

\section{Pancreas insulin contents}

At the age of 28 weeks, the pancreatic insulin contents were significantly lower in the O-C rats than in the LETO rats. In the O-P rats, the amount of pancreatic insulin content was almost doubled compared to the O-C rats $(22.9 \pm 1.2(v s) 11.4 \pm 1.1 \mathrm{nmol} /$ pancreas, $p<0.05$, Figure 3 ), and was significantly increased compared to those in the LETO rats. In the O-M rats, the pancreatic insulin content was also higher than the O-C rats but was not as high as in the O-P rats $(18.8 \pm 1.3$ (vs) $22.9 \pm 1.2 \mathrm{nmol} /$ pancreas in O-P rats, $p<0.05$, Figure 3).

\section{Histopathological changes}

The pancreata of the O-C rats were hypertrophic, the islet cells were increased in number and structurally disarranged with early fibrosis at the age of 28 weeks (Figure 4(B)). In the O-P rats, the structural changes in their pancreatic tissue were much less hypertrophic and fibrotic than that of the O-C rats (Figure $4(C)$ ). $\beta$ cell hypertrophy and fibrosis were also improved in the O-M rats, but compared with the O-P rats, more inflammatory cell infiltration and fibrosis were observed (Figure 4(D)).

\section{Discussion}

This study demonstrated that a chronic treatment with pioglitazone in pre-diabetic OLETF rats prevents the 
Pre-treatment

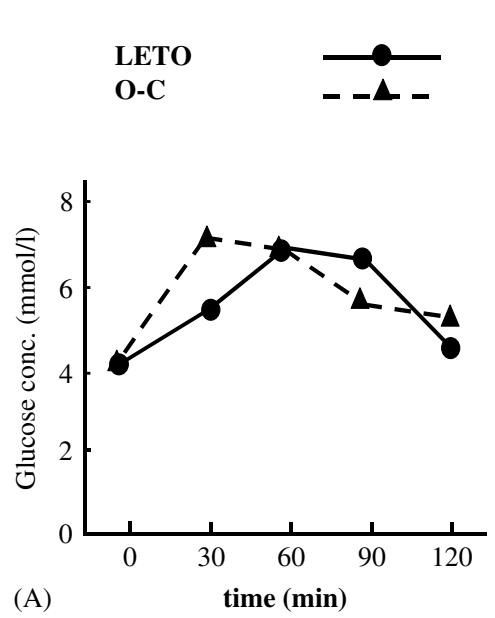

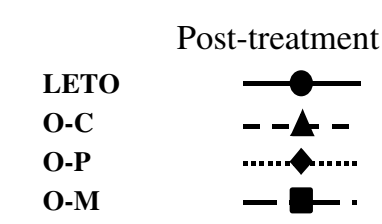

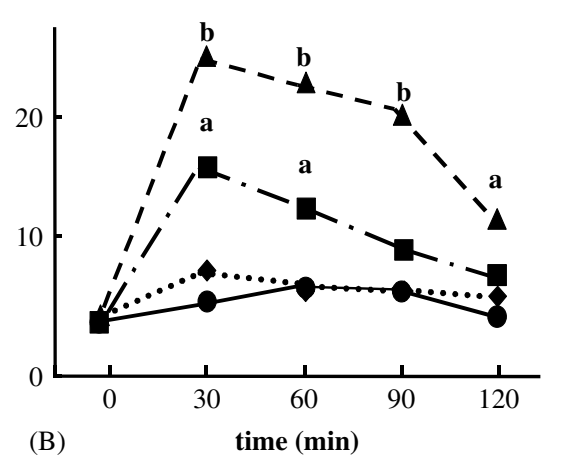

Figure 1. Plasma glucose concentrations before and after oral glucose $(2 \mathrm{~g} / \mathrm{kg})$ load at pre-treatment (A) at the age of $18 \mathrm{weeks}$ and post-treatment (B) at 28 weeks in LETO rats (LETO) and control-OLETF rats (O-C), the pioglitazone- (O-P) and the metformin(O-M) treated rats. a $p<0.05(v s)$ LETO rats; $\mathrm{b} p<0.001$ ( $v s)$ LETO rats

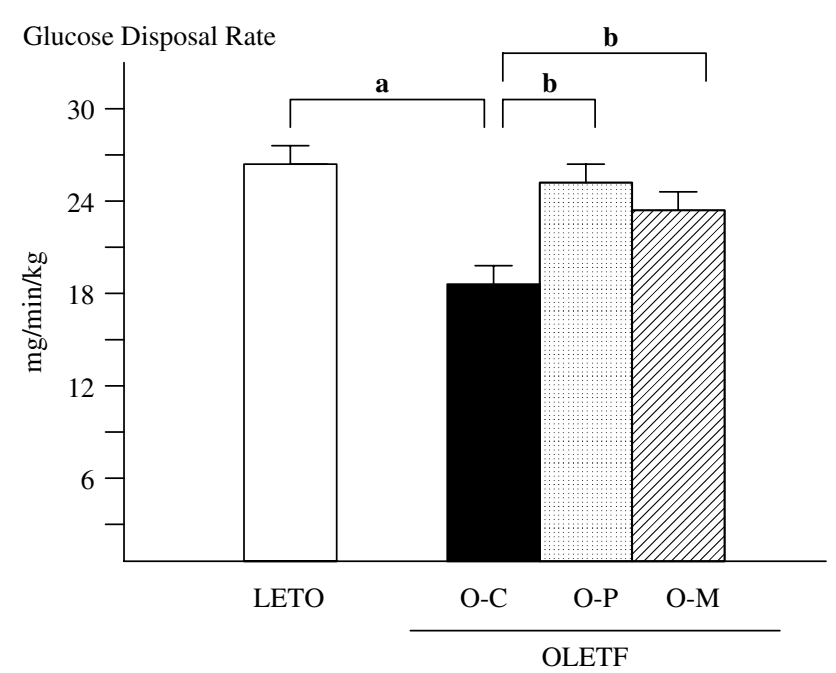

Figure 2. Glucose disposal rate (GDR) calculated during a euglycaemic hyperinsulinaemic clamp after a 10-week treatment of pioglitazone and metformin. a $p<0.05$ ( $v s$ ) LETO rats (LETO); b $p<0.05(v s)$ control-OLETF rats (O-C). O-P, the pioglitazone treated OLETF rats; O-M, the metformin treated OLETF rats

development of diabetes, normalizes hyperlipidaemia and increases pancreatic insulin contents despite the prominent body weight gain. On the other hand, a long-term treatment with metformin during the pre-diabetic stage in OLETF rats does not completely reverse hyperglycaemia after glucose loading, but significantly improves glucose utilization with marked weight reduction.

A previous study showed that the long-term administration of troglitazone in the OLETF rats prevents diabetes and insulin secretory defects. However, they did not report the marked weight changes in the troglitazone treated rats [7]. PPAR- $\gamma$ agonist is known to promote preadipocyte growth and differentiation with subcutaneous adipocytes being more specific than visceral adipocytes, which results in a greater number of smaller, more insulin sensitive

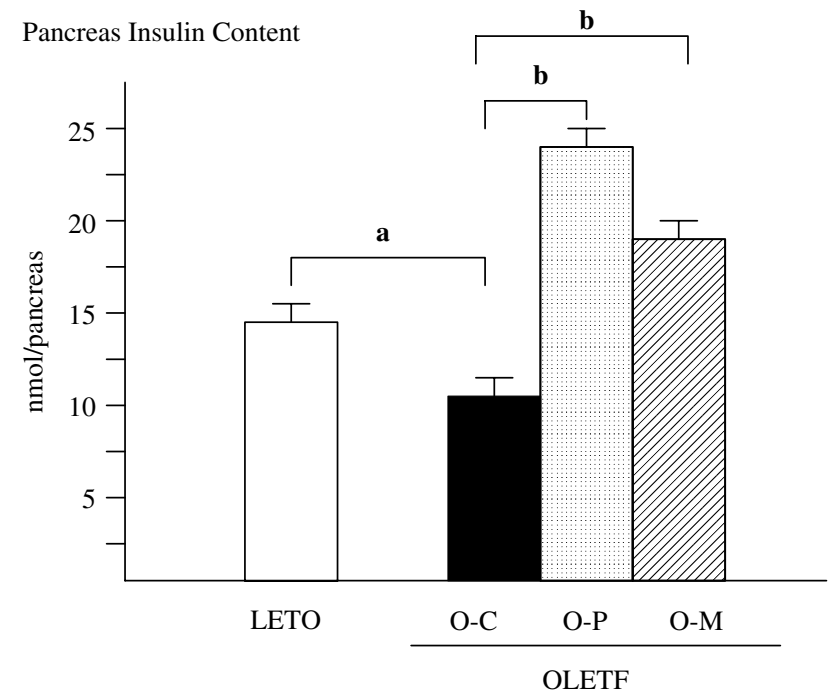

Figure 3. Pancreas insulin contents after a 10-week treatment of pioglitazone and metformin. a $p<0.05$ (vs) LETO rats (LETO); b $p<0.05(v s)$ control-OLETF rats (O-C). O-P, the pioglitazone treated OLETF rats; O-M, the metformin treated OLETF rats

cells $[21,22]$. In this study, after 10 weeks of pioglitazone administration, the OLETF rats show a marked weight gain, but the increased fat portions were mainly found in the subcutaneous fats rather than in the metabolically deleterious visceral fats (Table 1). Miyazaki et al. reported that a shift in the fat distribution from the visceral or other area to subcutaneous adipose depots after a pioglitazone treatment is associated with an improvement in the hepatic and peripheral tissue sensitivity to insulin in type 2 diabetic patients [21]. This can explain the normal glucose tolerance in the pioglitazone-treated OLETF rats, despite their significant body weight gain in this study.

In contrast, the metformin treated groups show a marked weight reduction compared to both the LETO and the other OLETF groups in this study. The marked 

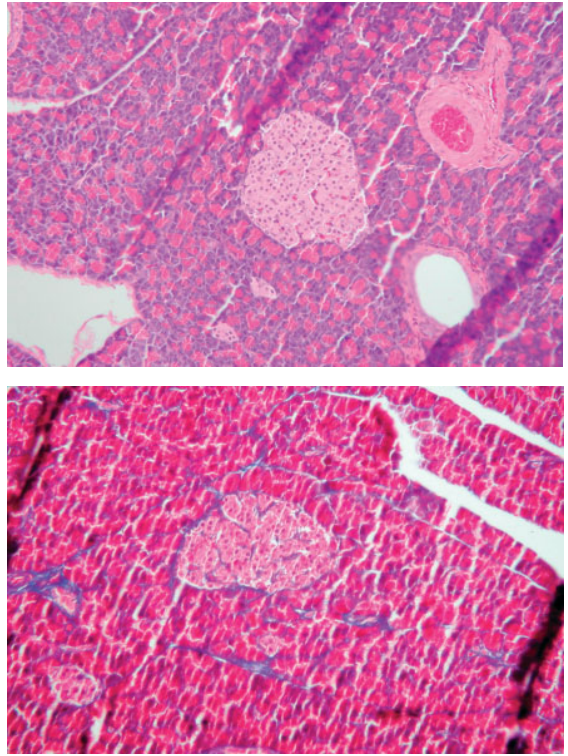

(A)
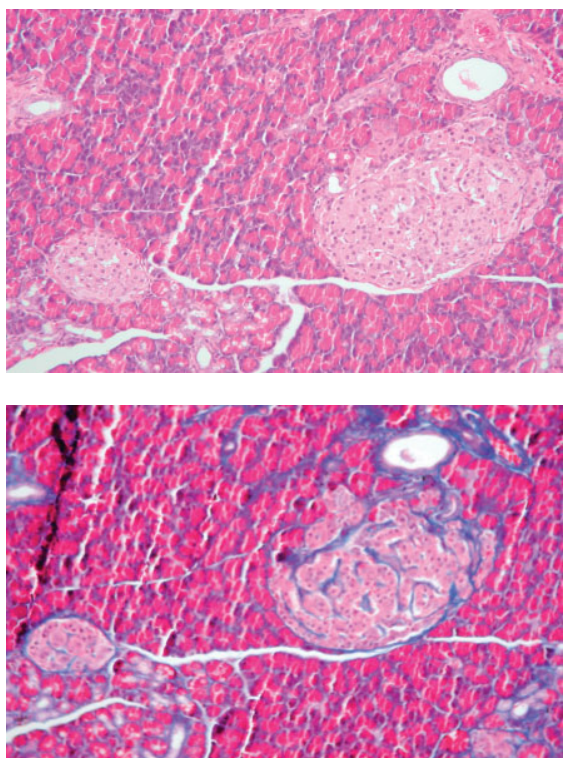

(C)
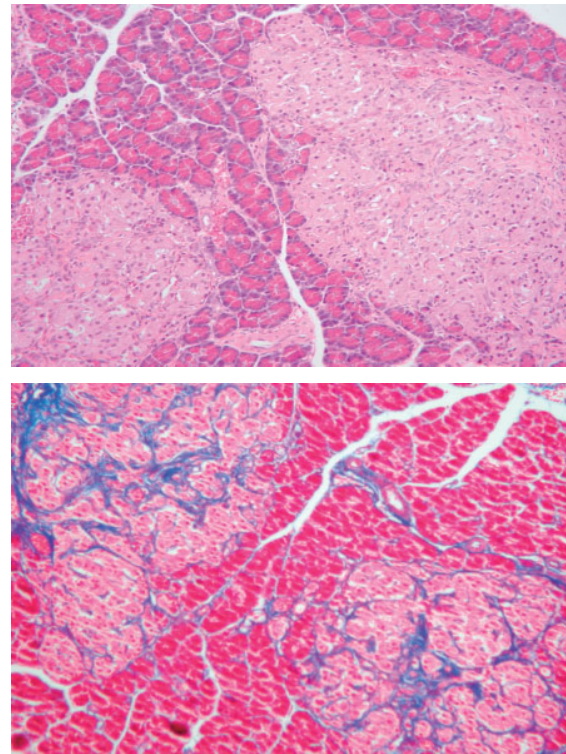

(B)
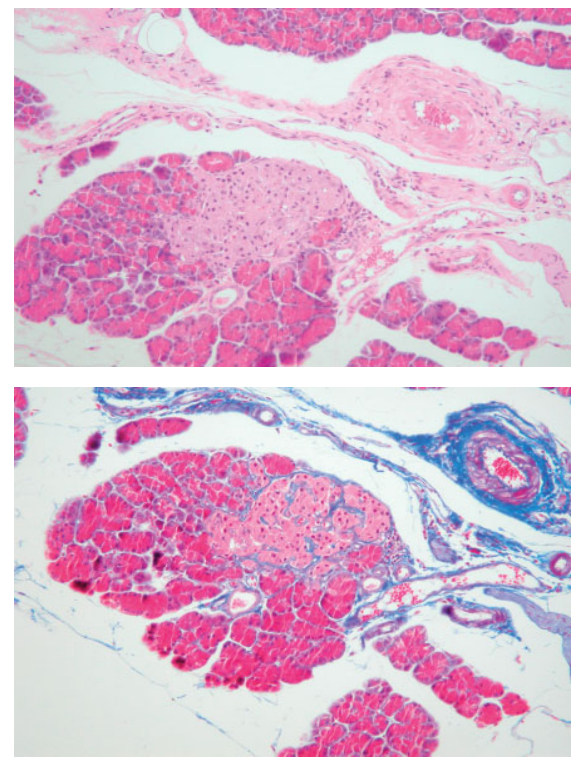

(D)

Figure 4. Morphologic features of pancreatic islet cells at 28 weeks of age. A. LETO rats (LETO): Normal islets of LETO rat at 28 weeks. (A1. Hematoxylin-eosin stain, x200, A2. Masson's trichrome stain, x 200) B. control-OLETF rats (O-C): Enlarged hyperplastic islets of OLETO rat at 28 weeks. Increased numbers of islets cells and irregular fibrous strands separating the lobules into clusters are noted. (B1. Hematoxylin-eosin stain, x 200, B2. Masson's trichrome stain, $x 200$ ) C. pioglitazone-OLETF rats (O-P): Slightly hyperplastic islets separated into clusters by thin fibrous bands are noted. Compared with B, a lesser degree of fibrosis is seen (C1. Hematoxylin-eosin stain, x 200, C2. Masson's trichrome stain, x 200) D. metformin-OLETF rats (O-M): Slightly hyperplastic islets separated into clusters by relatively thin fibrous bands with mild lymphocytic infiltration are noted. (D1. Hematoxylin-eosin stain, $\times 200$, D2. Masson's trichrome stain, $\times 200$ )

reduced body weight arose mainly from the decreased visceral fat content (Table 1). In other studies, metformin administration can lower blood pressure in the OLETF rats with an improvement in the insulin resistance and triglyceridaemia with a prominent weight reduction $[17,23]$. Overall, metformin can ameliorate the insulin resistance in the OLETF rats possibly through the marked reduction in the visceral fats and enhancing the glucose utilization.

Hypertriglyceridaemia is known to reduce the amount of peripheral glucose utilization [24,25], inhibit glucose-stimulated insulin release $[25,26]$ and promote hepatic glucose production. Elevated triglyceride levels and ectopic fat accumulation are commonly observed in type 2 diabetes cases, and they have direct detrimental effect on the pancreatic beta cells, termed lipotoxicity $[12,26]$. Therefore, an intensive correction of the dyslipidaemia can improve the insulin resistance and the beta cell function in type 2 diabetes [27-33]. OLETF rats develop visceral obesity and hypertriglyceridaemia at approximately 6 weeks, which is an age before glucose intolerance had been manifested [29]. In the course of 
diabetes in the OLETF rats, hypertriglyceridaemia might result in significant triglyceride storage in islets, which cause insulin secretion defects possibly by reducing the glucokinase activity [3].

In this study, the dramatic effects of pioglitazone in lowering the FFAs, total cholesterol and triglyceride levels in the OLETF rats were observed. Pioglitazone reverses the serum triglyceride and FFAs levels to completely normal levels beyond the range in the non-diabetic LETO rats. Metformin also has a beneficial effect on the lipid profiles, but a marked reduction as observed in the pioglitazone treated groups, was not observed (Table 1).

We performed a hyperinsulinaemic euglycaemic clamp test for measuring the level of glucose utilization in the skeletal muscle [19]. The glucose disposal rate was significantly improved after the pioglitazone and metformin treatment, respectively, compared to the O$\mathrm{C}$ rats (Figure 2). When compared to previous studies, thiazolidinediones alone or combined with sulfonylurea improves both the glucose disposal rate in the skeletal muscle and beta cell function in the pancreas [28,33].

The pancreatic islet cells of the OLETF rats have periodic morphological changes according to their age, (1) a near normal stage with some sporadic changes in the same lobule, (2) large islet cells with hyperplasia of beta cells in the prediabetic period, (3) atrophy of the hyperplastic foci and a loss of beta cells in the later stage, (4) dense fibrosis and clustering of the islet cells [34]. The pancreas insulin content and histomorphological changes were measured at the age of 28 weeks in the OLETF rats. At that stage, hyperplastic pancreatic islet cells were observed in the OLETF rats, which were forced to secrete more insulin to overcome their loss of normal insulin sensitivity [34-36].

It was interesting that we observed the conservation of pancreatic islet changes, from such change as islet hypertrophy and early fibrosis, in the O-P rats. We also observe the improvement of islets in the O-M rats, but more fibrotic changes than the pioglitazone treated group. This pathological improvement after 10 weeks of pioglitazone treatment might contribute that the pancreatic insulin content almost doubled compared to the O-C and non-diabetic LETO rats (Figure 3, Figure 4). Considering that the pancreatic insulin content reflects the endogenous beta cell function precisely [33,34], the chronic treatment of pioglitazone during the pre-diabetic periods in the OLETF rats can preserve and compensate for the beta cell function with ameliorating the morphological deterioration of the pancreatic islets [36,37].

Our study has several limitations. First, we did not measure pancreatic TG contents in the pancreas of sacrificed animals, which could explain the direct effect of pioglitazone on the extra-fat deposition in pancreas and the beta cell function with normalizing serum lipid profile in OLETF rats. Second, we did not measure adipocytokines, such as leptin, adiponectin, IL-6 etc., which could influence the different mechanisms between pioglitazone and metformin treatment on the body weight changes and the fat redistribution of OLETF rats in this study.
The pre-diabetic long-term treatment with pioglitazone improves the postglycaemic insulin response at a normal level and completely prevents the development of diabetes in a type 2 diabetic OLETF rat model despite marked weight gain. The pancreatic insulin contents were doubled with preservation of islet cell pathology with the dramatic normalization of the dyslipidaemia and fat redistribution, which plays a different role in preventing diabetes in this model compared to the metformin treatment.

On the other hand, the chronic treatment of metformin in the prediabetic stage also improves fasting and postglycaemic glucose response, but not upto the level of the pioglitazone treated groups, which occurred mainly as a result of an improvement in visceral obesity with a marked weight reduction and by the enhancement of glucose utilization in the peripheral tissue.

\section{Acknowledgements}

This study was supported by a grant of the Korea Health 21 R \& D Project, Ministry of Health and Welfare, Republic of Korea (02-PJ1-PG10-20908-0005). We are very grateful to Dr Yoon Jung Choi, Department of Pathology at National Health Insurance Coporation Ilsan hospital, Korea, for all pathological examinations and comments.

\section{References}

1. Diabetic Prevention Program Research Group. Reduction in the incidence of type 2 diabetes with life style intervention or metformin. N Engl J Med 2002; 346: 393-403.

2. Kawano K, Hirashima T, Mori S, Saitoh Y, Kurosumi M, Natori T. Spontaneous long-term hyperglycemic rat with diabetic complication. Otsuka Long-Evans Tokushima Fatty (OLETF) strain. Diabetes 1992; 41: 1422-1428.

3. Man ZW, Zhu M, Noma Y, et al. Impaired $\beta$-cell function and deposition of fat droplets in the pancreas as a consequence of hypertriglyceridemia in OLETF rat, a model of spontaneous NIDDM. Diabetes 1997; 46: 1718-1734.

4. Nolan JJ, Ludvik B, Beerdsen P, Joyce M, Olefsky J. Improvement of glucose tolerance and insulin resistance in obese subjects treated with troglitazone. N Engl J Med 1994; 331: 1188-1193.

5. Antonucci T, Whitcomb R, McLain R, Lockwood D, Norris RM. Impaired glucose tolerance is normalized by treatment with the thiazolidinedione troglitazone. Diabetes Care 1997; 20: 188-193.

6. The Diabetes Prevention Program Research Group. The Diabetes Prevention Program; design and methods for a clinical trial in the prevention of type 2 diabetes. Diabetes Care 1999; 22: 623-634.

7. Jia DM, Tabaru A, Nakamura H, Fukumitsu KI, Akiyama T, Otsuki M. Troglitazone prevents and reverses dyslipidemia, insulin secretory defects, and histologic abnormalities in a rat model of naturally occurring obese diabetes. Metabolism 2000; 49: 1167-1175.

8. Durbin RJ. Thiazolidinedione therapy in the prevention/delay of type 2 diabetes in patients with impaired glucose tolerance and insulin resistance. Diabetes Obes Metab 2004; 6(4): 280-285.

9. Saltiel AR, Olefsky JM. Thiazolidinediones in the treatment of insulin resistance and type II diabetes. Diabetes 1996; 45: 1661-1669.

10. Torra IP, Chinetti G, Duval C, Fruchart JC, Staels B. Peroxisome proliferator-activated receptors: from transcriptional control to clinical practice. Curr Opin Lipidol 2001; 12: 245-254.

11. Aronoff S, Rosenblatt S, Braithwaite S, Egan KW, Mathisen AL, Schneider RL. Pioglitazone hydrochloride monotherapy improves glycemic control in the treatment of patients with 
type 2 diabetes: a 6-month randomized placebo-controlled doseresponse study. The Pioglitazone 001 Study Group. Diabetes Care 2000; 23: 1605-1611.

12. Young PW, Cawthorne MA, Colyle PJ, et al. Repeat treatment of obese mice with BRL 49653, a new potent insulin sensitizer, enhances insulin action in white adipocytes. Association with increased insulin binding and cell-surface GLUT4 as measured by photoaffinity labeling. Diabetes 1995; 44: 1087-1092.

13. Cgawka A, Schwarz EJ, Dimaculangan DD, Lazar MA. Peroxisome proliferator-activated receptor (PPAR) gamma: adiposepredominant expression and induction early in adipocyte differentiation. Endocrinology 1996; 137: 4189-4195.

14. Lewis GF, Carpentiew A, Adeli K, Giacca A. Disordered fat storage and mobilization in the pathogenesis of insulin resistance and type 2 diabetes. Endocr Rev 2002; 23: 201-229.

15. Lee CE, Olsen P, Evans RM. Minireview: lipid metabolism, metabolic diseases, and peroxisome proliferator-activated receptors. Endocrinology 2003; 144: 2201-2207.

16. Sreenan S, Sturis J, Pugh W, Burant CF, Polonsky KS. Prevention of hyperglycemia in the Zucker diabetic fatty rat by treatment with metformin or troglitazone. Am J Physiol 1996; 271: 742-747.

17. Kosegawa I, Chen S, Awata T, Negishi K, Katayama S. Metformin decreases blood pressure and obesity in OLETF rats via improvement of insulin resistance. Hypertens Res 1996; 19(1): 37-41.

18. Knowler WC, Barrett-Connor E, Fowler SE, et al. Reduction in the incidence of type 2 diabetes with lifestyle intervention or metformin. N Engl J Med 2002; 246(6): 393-403.

19. Cha BS, Ahn CW, Song YD, et al. Chronic alcohol intake differently influences glucose metabolism according to nutritional status. J Clin Endocrinol Metab 2000; 85: 3646-3652.

20. Pospisilik JA, Stafford SG, Demuth HU, MaLntosh CH, Pederson RA. Long-term treatment with dipeptidyl peptidase IV inhibitor improves hepatic and peripheral insulin sensitivity in the VDF zucker rat; A euglycemic hyperinsulinemic clamp study. Diabetes 2002; 51: 2677-2683.

21. Miyazaki Y, Mahnkali A, Matsuda M, et al. Effect of pioglitazone on abdominal fat distribution and insulin sensitivity in type 2 diabetic patients. J Clin Endocrinol Metab 2002; 87: 2784-2791.

22. Spiegelman BM. PPAR-gamma, adipogenic regulator and thiazolidinedione receptor. Diabetes 1995; 44: 1087-1092.

23. Kosegawa I, Chen S, Awata T, Negishi K, Katayama S. Troglitazone and metformin, but not glibenclamide, decrease blood pressure in Otsuka Long Evans Tokushima Fatty rats. Clin Exp Hypertens 1999; 21: 199-211.

24. Boden G. Role of fatty acids in the pathogenesis of insulin resistance and NIDDM. Diabetes 1996; 45: 3-10.
25. Mingrone G, Henriksen FL, Greco AV, et al. Triglycerideinduced diabetes associated with familial lipoprotein lipase deficiency. Diabetes 1999; 48: 1258-1263.

26. Shimabukuro M, Zhou Y-T, Lee Y, Unger RH. Troglitazone lowers islet fat and restores beta cell function of Zucker diabetic fatty rats. J Biol Chem 1998; 273: 3547-3550.

27. Paolisso G, Howard BV. Role of non-esterified fatty acids in the pathogenesis of type 2 diabetes mellitus. Diabet Med 1998; 15: 360-366.

28. Mattews DR, Bakst AW, Weston WM. Rosiglitazone decreases insulin resistance and improves beta-cell function in patients with type 2 diabetes. Diabetologia 1999; 42: A228.

29. Man ZW, Kawano K, Tsukasa H, Hirsashima T, Mori S, Shima K. Hypertriglyceridemia as a Risk Factor which Causes Abnormal Insulin Secretion in the OLETF Rat. 1999; Obesity and NIDDM: Lessons from OLETF rat 55-65.

30. Young PW, Buckle DR, Cantello BC, Chapman H, Clapham JC, Smith SA. Identification of high-affinity binding sites for the insulin sensitizer rosiglitazone (BRL-49653) in rodent and human adipocytes using a radioiodinated ligand for peroxisomal proliferator-activated receptor gamma. J Pharmacol Exp Ther 1998; 284: 751-769.

31. Mathisen A, Geerlof G, Houser V. The effect of pioglitazone on glucose control and lipid profile in patients with type 2 diabetes. Diabetes 1999; 48: A102-A103.

32. Raskin P, Rappaport EB, Cole ST, Yan Y, Pataardhan T, Freed MI. Rosiglitazone short-term monotherapy lowers fasting and post-prandial glucose in patients with type II diabetes. Diabetologia 2000; 43: 278-284.

33. Woffenbuttel BH, Gomis R, Squatrito S, Jones NP, Patwardhan RN. Addition of low-dose rosiglitazone to sulphonylurea therapy improves glycemic control in Type 2 diabetic patients. Diabet Med 2000; 17: 40-47.

34. Jimi A, Miyasaka K, Shinozaki H, Fimalpsjo A. Morphological Changes in the Pancreatic Islets of the OLETF Rat. 1999; Obesity and NIDDM: Lessons from the OLETF rat 29-36.

35. Movassat J, Saulnier C, Serradas P, Partha B. Impaired development of pancreatic beta-cell mass is a primary event during the progression to diabetes in the GK rat. Diabetologia 1997; 140: 916-925.

36. Zhu M, Noma Y, Mizuno A, Sano T, Shima K. Poor capacity for proliferation of pancreatic beta-cells in Otsuka Long-Evans Tokushima Fatty rat. A model of spontaneous NIDDM. Diabetes 1996; 45: 941-960.

37. Smith SA, Lister CA, Toseland CDN, Buckingham RE. Rosiglitazone prevents the onset of hyperglycemia and proteinuria in the Zucker diabetic fatty rat. Diabetes Obes Metab 2000; 2: 363-372. 